\title{
The Balance between Oral Health Needs and Supply Induced Demand in Welsh Dental Services
}

\author{
Wayne Richards a (D), Jamal Ameen ${ }^{b}$, Anne-Marie Coll ${ }^{c}$, Teresa Filipponi ${ }^{c}$ \\ a Professor Community General Dental Practice, University of South Wales, Faculty of Life Sciences and Education, Glyntaff, Pontypridd, \\ CF37 4BD, Wales. \\ ${ }^{\mathrm{b}}$ Emeritus Professor Statistics, University of South Wales, Faculty of Life Sciences and Education, Glyntaff, Pontypridd, CF37 4BD, Wales. \\ ${ }^{\mathrm{c}}$ Senior Lecturer, University of South Wales, Faculty of Life Sciences and Education, Glyntaff, Pontypridd, CF37 4BD, Wales.
}

\begin{abstract}
Introduction: Reducing social inequality along with oral health inequality in Wales, is a policy objective. In this ecological study, the relationships between deprivation, dental workforce, and oral health are explored.

Methods: Twenty-two Unitary Authorities (UAs) serving the population of Wales were studied. The number of dentists was obtained from NHS Business Services as well as the 2019 population figures from StatsWales. As data for whole time equivalent General Dental Practitioner (GDP) workforce were not available, GDP sites were used. The condition of teeth at the age of 12 years was used as a measure of oral health from the most recent epidemiological survey available. The relationship between oral health and workforce was established using the Welsh Index of Multiple Deprivation (WIMD).

Results: Associations were observed between dental sites and population as well as between oral health and deprivation. A new composite variable called the University of South Wales Dental Index (USWDI) was introduced by combining the number of dentists with their corresponding WIMD of the most deprived $10 \%$ of the population. Using regression modelling the USWDI demonstrated its superiority in using either the number of dentists or the WIMD most deprived $10 \%$ alone to predict decayed, missing, and filled teeth (DMFT).

Conclusion: Workforce levels have increased, and there has been a corresponding improvement in oral health over two decades. At the same time, deprived subgroups continue to experience relatively higher levels of disease. A proportion of the general dental services delivered in Wales has continued to be based on the principle of supply induced demand for care rather than oral health need. Improving oral health in a diverse population like Wales cannot be achieved by increasing dental workforce alone. It is necessary to account for levels of deprivation. USWDI as a predictor of DMFT could be a useful tool to monitor the macro delivery of oral health care for the future in Wales.
\end{abstract}

KEYWORDS: Dental Workforce, Deprivation, Oral Health, Correlation, Regression Analysis, Prevention.

Correspondence: Pr Richards Wayne. University of South Wales, Faculty of Life Sciences and Education, Glyntaff, Pontypridd, Wales. Email: wayne.richards@southwales.ac.uk

Copyright $\odot 2021$ Richards W et al. This is an open access article distributed under the Creative Commons Attribution 4.0 International, which permits unrestricted use, distribution, and reproduction in any medium, provided the original work is properly cited.

\section{INTRODUCTION}

Research has indicated a significant correlation between the state of oral health and levels of socio-economic status [1-4]. Watt \& Sheiham (1999) demonstrated that the increased provision of workforce should carefully account for socio-economic status [5].

In Spain, the number of dentists per head of population increased dramatically over the last decade of the 20th century in bringing dental workforce in line with other European countries. Yet concern had been reported that this increase in workforce brought a demand for care that was not based on health need but rather on cosmetic, elective treatments, and sometimes outdated care modalities [6]. The concept of supply induced demand has been reported in the British literature in the context of rewarding dentists $[7,8]$. Therefore, supply and demand should be accompanied by the consideration of oral health needs [9].

Since 1990 an extensive literature has accumulated suggesting that UK delivery systems and consequent rewards for general dental practitioners are outdated. Important issues highlighted were the need to address the frequency of attendance for oral health monitoring, the value of routine prophylaxis, caries management and continuing care [10-18]. Following the Health and Social Care Bill [19] a new dental contract for GDPs in England and Wales was established in 2006 [20]. The new 
contract placed commissioning of oral healthcare with Primary Care Organisations (PCO). In Wales, the PCO is known as the Local Health Board (LHB).

The commissioning of oral healthcare provided an opportunity for both the dentists and LHBs to satisfy their respective professional roles with improved health outcomes for the community. There was an opportunity for dentists to develop a new mindset outside the "fee per item' constraints. Furthermore, it had been suggested that local health agencies should form partnerships with dental practitioners through service level agreements that foster equitable health outcomes. However, there were unintended consequences resulting from the contract of 2006, where lower socio-economic groups were no longer attractive patients for GDPs, making access for care difficult for this sub-group in the community [21]. During this period, the treatment demands from communities continued to satisfy the supply of care provided by GDPs, where GDPs were kept occupied through performing interventions that were not totally based on oral health needs.

In order for Welsh Government in conjunction with LHBs to fulfill their health remit for dental care, decision-making regarding the supply of dentists should not only be based on the demand for dental care from the populations served, but it is necessary for supply induced demand to be considered.

This paper aims to explore the relationship between dental workforce, oral health, and deprivation to conclude the need for balancing between service provision for oral healthcare based on oral health need and supply induced demand.

\section{METHODS}

This ecological study was a follow up of a survey carried out by the first three authors in 2004 [22]. The study examines the twenty-two Unitary Authorities (UA) collectively serving the population of Wales. Workforce levels were established for each of the seven LHBs. Furthermore, the number of GDP sites and Community Dental Service (CDS) sites were used for each UA. The Welsh Index of Multiple Deprivation (WIMD) was used to measure deprivation [23]. Associations between dental workforce, oral health, and deprivation were investigated. Measures of Pearson Correlation were used to establish the strength of their relationship with oral health. The findings were further explored using linear regression, incorporating workforce and deprivation to explain oral health. IBM SPSS 27 software was used for data analysis. Oral Health Need

The condition of teeth at the age of 12 years will, to a large extent, determine the future dental health of emerging population cohorts of young adults [24]. Figures based on Wales data in 2016/7 have been used to measure caries for this age group [25]. It is recognised that caries are distributed unevenly in communities, with most of the disease concentrated in a small percentage of the population. The mean decayed, missing, and filled teeth index (DMFT) along with the DMFT calculated for those experiencing disease have been used for analysis. The percentage of the 12-year-olds population with disease experience (DMFT >0) was also established for all the UAs in the LHBs.

\section{Deprivation}

The WIMD was used to measure deprivation [23]. The WIMD ranks 1909 Lower Super Output Areas (LSOA) in Wales. Each LSOA has a population in the region of 1600. Every LSOA has been scored according to 8 measures. These are Income, Employment, Health, Education, Access to services, Community safety, Physical environment and Housing. From these scores, an overall score is provided for each LSOA, and these are ranked from 1 most deprived to 1909 least deprived. The index is specifically constructed for Wales as a relative measure of deprivation within the country. Measures have been calculated at the UA level for the average rank, most $10 \%$ deprived and most $50 \%$ deprived in Wales.

\section{Workforce}

In order to compute the number of dentists per 1000 population in the 22 Welsh UAs, datasets were obtained from the NHS Business Services for 2018/9 [26]. A dataset of the 2019 population figures for UAs was obtained from the Welsh Government [27].

In the absence of data for whole time equivalent GDP workforce, to overcome the problem of multiple contracts per dentist and skill mix per practice, GDP sites were used for analysis. These were found to be more stable, taking into account part-time working in multiple locations. GDP sites were obtained from LHBs [28]. Subsequently, further analysis was undertaken using combined GDP and CDS sites. CDS sites were obtained from a telephone enquiry to clinical directors of services. Statistical Analysis

Pearson Correlation coefficients were used to examine the relationship between measures of deprivation, dental workforce, and oral health.

A new composite variable called the University of South Wales Dental Index (USWDI) was introduced by combining the number of dentists with their corresponding WIMD most deprived $10 \%$ of the population. The USWDI was used to build regression models expressing the index of oral health in parallel to the existing measures of deprivation and dental workforce to demonstrate its superiority in using either of the numbers of dentists or the WIMD most deprived $10 \%$ alone for predicting DMFT.

\section{RESULTS}

Wales has a population of 3.15 million people. The communities served by the seven LHBs, at UA level, range from 60326 to 366903 inhabitants. An average of 0.579 dentists per 1000 population serves the population of Wales. For the UAs the number of dentists per 1000 ranges from 0.397 to 0.878 . There are 22 UAs as shown in Figure 1. One LHB has one UA, two have two UAs, three have three UAs, one has five UAs and one has six UAs.

Table 1 and 1a show workforce and workforce sites and their associations. GDP sites correlated with population $(\mathrm{r}=0.959, \mathrm{p}=0.000)$ as did CDS sites $(\mathrm{r}=0.654, \mathrm{p}=0.001)$ and combined GDP and CDS sites $(\mathrm{r}=0.958, \mathrm{p}=0.000)$. The number of dentists correlated with the number of GDP sites $(r=0.942, p=0.000)$. No correlation was found between the number of Dentists per 1000 population and the dental practice sites when comparing both GDS sites per 1000 population and combined GDP and CDS sites 
per 1000 population. However, a significant correlation was observed $(\mathrm{r}=0.982, \mathrm{p}=0.000)$ when GDP sites were compared with combined GDP and CDS sites, as was the case for GDP and CDS sites ( $r=0.607, p=0.003$ ). Moreover, CDS sites correlated with combined GDP and CDS sites $(r=0.744, p=0.000)$. The number of dentists correlated with population $(\mathrm{r}=0.950, \mathrm{p}=0.000)$. Population also correlated with \%Diseased $(\mathrm{r}=-0.450, \mathrm{p}=$ $0.035)$. Also, the \%Diseased correlated with GDP sites $(\mathrm{r}=-0.464, \mathrm{p}=0.029)$ and combined GDP and CDS sites $(\mathrm{r}=-0.471, \mathrm{p}=0.027)$. No significant correlation was observed between the number of dentists per 1000 population and either DMFT, DMFT for those with disease or \% Diseased.

Table 2 and 2 a show oral health measures and area deprivation scores and their associations. In table $2 \mathrm{a}$ significant correlations were found between the measures of disease: DMFT vs \%Diseased $r=0.953, p=0.000$; DMFT vs DMFT for those diseased $r=0.471, p=0.027$. Also, significant correlations were found between deprivation scores: WIMD rank average vs WIMD $10 \%$ $\mathrm{r}=-0.689, \mathrm{p}=0.000$; WIMD rank average vs WIMD $50 \%$ $\mathrm{r}=-0.0 .967, \mathrm{p}=0.000$; WIMD $10 \%$ vs WIMD $50 \%$ $\mathrm{r}=0.733, \mathrm{p}=0.000$.
When comparing disease measures with deprivation significant associations were observed:

DMFT vs WIMD rank average $\mathrm{r}=-0.653, \mathrm{p}=0.001$; DMFT vs WIMD 50\% r $=0.571, \mathrm{p}=0.005$; \%Diseased vs WIMD rank average $\mathrm{r}=-0.636, \mathrm{p}=0.001$; \% Diseased vs WIMD 50\% $\mathrm{r}=0.545, \mathrm{p}=0.009$. No significant associations were established for DMFT vs WIMD 10\%; $\%$ Diseased vs WIMD 10\%; DMFT of those with disease vs WIMD rank average; DMFT of those with disease vs WIMD 10\%; DMFT of those with disease vs WIMD50\%.

The number of dentists per 1000 population did correlate with the WIMD $10 \%(\mathrm{r}=0.447, \mathrm{p}=0.037)$. As deprivation was found to be significantly associated with the oral health of 12-year-olds, the investigation of the number of dentists per corresponding WIMD most deprived $10 \%$ was undertaken. The USWDI showed significant correlation with each of GDP sites, CDS sites, GDSCDS sites and WIMD10\% $(\mathrm{r}=0.788, \quad \mathrm{p}=0.000$; $\mathrm{r}=0.489, \mathrm{p}=0.021 ; \mathrm{r}=0.78, \quad \mathrm{p}=0.000 ; \mathrm{r}=0.728, \quad \mathrm{p}=0.000)$ respectively. In addition, it was found to be a significant predictor $(\mathrm{R} 2=0.536)$ to DMFT alongside WIMD Average Rank score (Table 3), and Figures 2 and 3 show scatter plots demonstrating these associations.

Table 1 Workforce and workforce sites

\begin{tabular}{cccccccc}
\hline $\begin{array}{c}\text { Unitary } \\
\text { Authority }\end{array}$ & $\begin{array}{c}\text { Number of } \\
\text { Dentists }\end{array}$ & $\begin{array}{c}\text { Pop mid yr } \\
\mathbf{2 0 1 9}\end{array}$ & $\begin{array}{c}\text { Ratio of } \\
\text { dentists/1000 }\end{array}$ & GDS sites & $\begin{array}{c}\text { GDS + CDS } \\
\text { sites }\end{array}$ & $\begin{array}{c}\text { Ratio GDP } \\
\text { sites /1000 }\end{array}$ & $\begin{array}{c}\text { Ratio } \\
\text { GDP+CDS } \\
\text { sites/1000 }\end{array}$ \\
\hline $\begin{array}{c}\text { Bridgend } \\
\text { Neath Port } \\
\text { talbot }\end{array}$ & 88 & 147049 & 0.59844 & 19 & 23 & 0.12921 & 0.15641 \\
Swansea & 90 & 143315 & 0.62799 & 17 & 28 & 0.11862 & 0.18142 \\
Blaenau & 183 & 246993 & 0.74091 & 41 & 46 & 0.166 & 0.18624 \\
Gwent & 39 & 69862 & 0.5153 & 10 & 14 & 0.14314 & 0.2004 \\
Caerphilly & 101 & 181075 & 0.54673 & 23 & 27 & 0.12702 & 0.14911 \\
Monmouth & 50 & 94590 & 0.50745 & 15 & 17 & 0.15858 & 0.17972 \\
Newport & 83 & 154676 & 0.49135 & 21 & 23 & 0.13577 & 0.1487 \\
Torfaen & 67 & 93961 & 0.60663 & 13 & 15 & 0.13836 & 0.15964 \\
Angelsey & 41 & 70043 & 0.58535 & 11 & 13 & 0.15705 & 0.1856 \\
Conwy & 59 & 117203 & 0.5034 & 15 & 19 & 0.12798 & 0.16211 \\
Denbigh & 84 & 95696 & 0.87778 & 9 & 12 & 0.09405 & 0.1254 \\
Flint & 75 & 156100 & 0.48046 & 17 & 21 & 0.1089 & 0.13453 \\
Gwynedd & 53 & 124560 & 0.4255 & 15 & 19 & 0.12042 & 0.15254 \\
Wrexham & 76 & 135957 & 0.559 & 15 & 19 & 0.11033 & 0.13975 \\
Cardiff & 265 & 366903 & 0.72226 & 51 & 61 & 0.139 & 0.16626 \\
Vale & 75 & 133587 & 0.56143 & 20 & 24 & 0.14972 & 0.17966 \\
Merthyr & 51 & 60326 & 0.84541 & 9 & 11 & 0.14919 & 0.182361 \\
RCT & 130 & 241264 & 0.53883 & 29 & 39 & 0.1202 & 0.16165 \\
Carmarthen & 101 & 188771 & 0.53504 & 24 & 31 & 0.12714 & 0.16422 \\
Ceredigion & 37 & 72695 & 0.50898 & 7 & 12 & 0.09629 & 0.16507 \\
Pemb & 50 & 125818 & 0.3974 & 17 & 23 & 0.13512 & 0.1828 \\
Powys & 75 & 132435 & 0.56632 & 24 & 33 & 0.18122 & 0.24918 \\
\hline & & & & & & & \\
\hline
\end{tabular}


Table 1a Workforce and workforce sites associations

\begin{tabular}{|c|c|c|c|c|c|c|c|c|}
\hline & GDP sites & CDS sites & $\begin{array}{l}\text { GDP+CDS } \\
\text { sites }\end{array}$ & Population & $\begin{array}{c}\text { GDP } \\
\text { sites/1000 } \\
\text { population }\end{array}$ & $\begin{array}{l}\text { GDP+CDS } \\
\text { sites/ 1000 } \\
\text { population }\end{array}$ & $\begin{array}{l}\text { Number } \\
\text { of Dentists }\end{array}$ & $\begin{array}{c}\text { Dentists / } \\
1000 \\
\text { popultion }\end{array}$ \\
\hline GDP sites & 1 & 0.607 & 0.982 & 0.959 & & & 0.942 & \\
\hline CDS sites & $0.607 * *$ & 1 & 0.744 & 0.654 & & & 0.566 & \\
\hline $\begin{array}{c}\text { GDP+CDS } \\
\text { sites }\end{array}$ & $0.982 * *$ & $0.744 * *$ & 1 & 0.958 & & & 0.926 & \\
\hline $\begin{array}{l}\text { Population } \\
\text { GDP sites/ }\end{array}$ & $0.959 * *$ & $0.654 * *$ & $0.958 * *$ & 1 & & & 0.95 & \\
\hline $\begin{array}{c}1000 \\
\text { population } \\
\text { GDP+CDS }\end{array}$ & & & & & 1 & 0.793 & & \\
\hline $\begin{array}{l}\text { sites/ } 1000 \\
\text { population }\end{array}$ & & & & & $0.793 * *$ & 1 & & \\
\hline $\begin{array}{l}\text { Number of } \\
\text { Dentists } \\
\text { Dentists/ }\end{array}$ & $0.942 * *$ & $0.566 * *$ & $0.926 * *$ & $0.950 * *$ & & & 1 & \\
\hline $\begin{array}{c}1000 \\
\text { population }\end{array}$ & & & & & & & & 1 \\
\hline $\begin{array}{c}\text { Total } \\
\text { Correlation }\end{array}$ & $\begin{array}{c}\text { Strong } \\
\text { Correlation }\end{array}$ & $\begin{array}{c}\text { Moderate } \\
\text { Correlation }\end{array}$ & $\begin{array}{l}* \text { * sig at } 0.05 \\
* * \text { sig at } 0.01\end{array}$ & & & & & \\
\hline
\end{tabular}

Table 2 Twelve year olds' Oral Health measures and Area Deprivation scores

\begin{tabular}{|c|c|c|c|c|c|c|}
\hline $\begin{array}{c}\text { Unitary } \\
\text { Authority }\end{array}$ & DMFT & $\begin{array}{c}\text { \%Diseased } \\
\text { 2016/7 }\end{array}$ & $\begin{array}{l}\text { DMFT with } \\
\text { disease }\end{array}$ & $\begin{array}{c}\text { WIMD } \\
\text { average Rank } \\
\text { score }\end{array}$ & WIMD $10 \%$ & WIMD $50 \%$ \\
\hline Bridgend & 0.47 & 25.1 & 1.86 & 927 & 7 & 56 \\
\hline $\begin{array}{c}\text { Neath Port } \\
\text { talbot }\end{array}$ & 0.70 & 36.2 & 1.93 & 728 & 15 & 69 \\
\hline Swansea & 0.52 & 25.8 & 2.01 & 1027 & 11 & 46 \\
\hline $\begin{array}{c}\text { Blaenau } \\
\text { Gwent }\end{array}$ & 1.10 & 51.0 & 2.15 & 528 & 13 & 85 \\
\hline Caerphilly & 0.95 & 39.6 & 2.39 & 816 & 10 & 63 \\
\hline Monmouth & 0.50 & 25.9 & 1.93 & 1272 & 0 & 20 \\
\hline Newport & 0.63 & 29.8 & 2.11 & 840 & 24 & 60 \\
\hline Torfaen & 0.94 & 49.2 & 1.92 & 850 & 5 & 57 \\
\hline Angelsey & 0.84 & 41.5 & 2.02 & 1034 & 2 & 39 \\
\hline Conwy & 0.52 & 24.3 & 2.13 & 1056 & 6 & 41 \\
\hline Denbigh & 0.71 & 36.0 & 1.97 & 945 & 12 & 47 \\
\hline Flint & 0.60 & 27.3 & 2.21 & 1208 & 3 & 32 \\
\hline Gwynedd & 0.63 & 34.3 & 1.83 & 1081 & 3 & 34 \\
\hline Wrexham & 0.70 & 29.6 & 2.35 & 1034 & 7 & 41 \\
\hline Cardiff & 0.41 & 21.6 & 1.88 & 984 & 18 & 49 \\
\hline Vale & 0.32 & 17.3 & 1.83 & 1255 & 4 & 35 \\
\hline Merthyr & 0.72 & 36.4 & 1.98 & 667 & 22 & 78 \\
\hline RCT & 0.66 & 30.1 & 2.18 & 743 & 18 & 71 \\
\hline Carmarthen & 0.45 & 22.4 & 2.03 & 891 & 4 & 54 \\
\hline Ceredigion & 0.49 & 28.3 & 1.74 & 1026 & 2 & 46 \\
\hline Pemb & 0.63 & 26.3 & 2.38 & 985 & 6 & 42 \\
\hline Powys & 0.41 & 23.4 & 1.74 & 1139 & 1 & 24 \\
\hline
\end{tabular}

Table 2a Oral Health and Deprivation associations

\begin{tabular}{|c|c|c|c|c|c|c|}
\hline & $\%$ Diseased & $\begin{array}{c}\text { DMFT for } \\
\text { diseased }\end{array}$ & DMFT & WIMD $10 \%$ & WIMD 50\% & $\begin{array}{c}\text { WIMD Rank } \\
\text { Average }\end{array}$ \\
\hline \% Diseased & 1 & & 0.953 & & 0.545 & -0.636 \\
\hline $\begin{array}{l}\text { DMFT for } \\
\text { diseased }\end{array}$ & & 1 & 0.471 & & & \\
\hline DMFT & $0.953 * *$ & $0.471^{*}$ & 1 & & 0.571 & -0.653 \\
\hline WIMD 10\% & & & & 1 & 0.733 & 0.689 \\
\hline WIMD 50\% & $0.545^{* *}$ & & $0.571 * *$ & $0.733 * *$ & 1 & -0.967 \\
\hline $\begin{array}{c}\text { WIMD Rank } \\
\text { Average }\end{array}$ & $-0.636 * *$ & & $-0.653 * *$ & $-0.689 * *$ & $-0.967 * *$ & 1 \\
\hline $\begin{array}{c}\text { Total } \\
\text { Correlation }\end{array}$ & $\begin{array}{c}\text { Strong } \\
\text { Correlation }\end{array}$ & $\begin{array}{c}\text { Moderate } \\
\text { Correlation }\end{array}$ & $\begin{array}{c}* \text { sig at } 0.05 \\
* * \text { sig at } 0.01\end{array}$ & & & \\
\hline
\end{tabular}




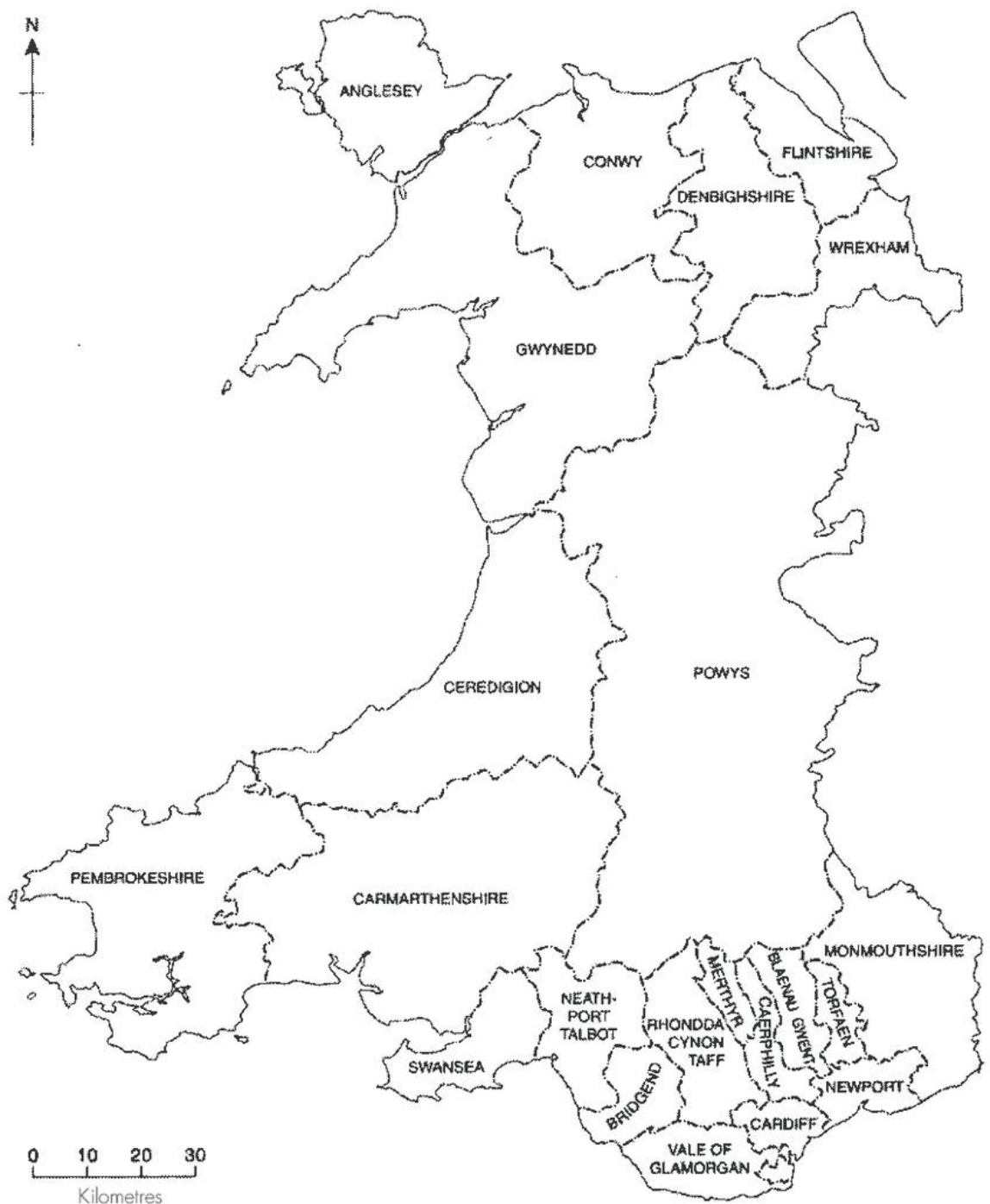

Figure 1 Unitary Authorities in Wales

1,1 e

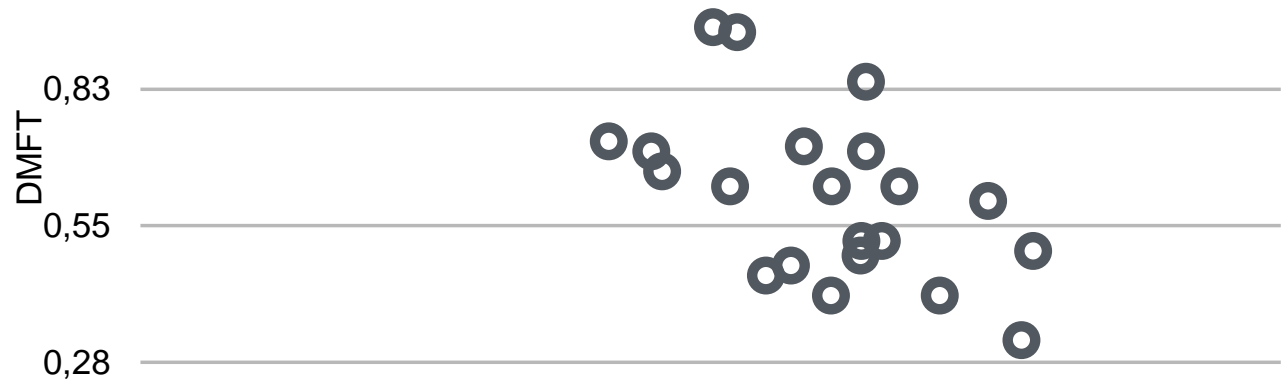

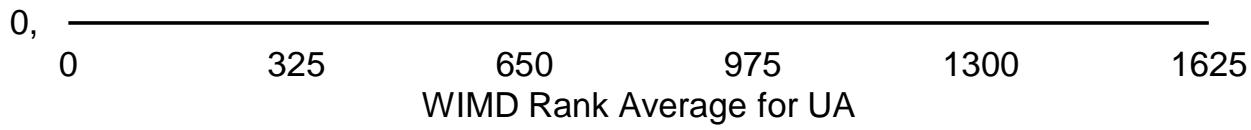

Figure 2 DMFT by WIMD Rank Average 


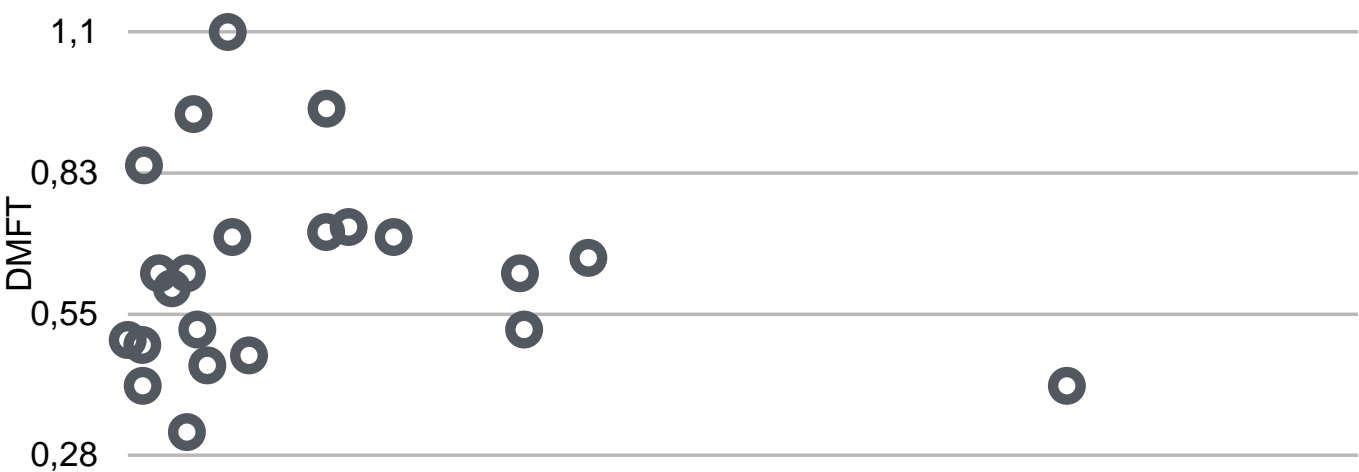

0 ,

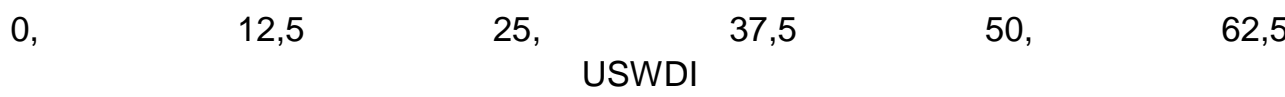

Figure 3 DMFT by USWDI

Table 3: Regression of DMFT as expressed by WIMD Average Rank \& USWDI

\begin{tabular}{llllll}
\hline & $\begin{array}{l}\text { Unstandardized } \\
\text { Coefficients B }\end{array}$ & Std. Error & $\begin{array}{l}\text { Standardized } \\
\text { Coefficients Beta }\end{array}$ & $\mathbf{t}$ & Sig. \\
\hline (Constant) & 1.43 & 0.173 & & 8.259 & 0 \\
WIMD Average & & & & & \\
Rank Score & -0.001 & 0 & -0.753 & -4.611 & 0 \\
USWDI & -0.006 & 0.003 & -0.344 & -2.11 & 0.048 \\
\hline
\end{tabular}

\section{DISCUSSION}

Reducing social inequality has been a priority for policy makers $[15,16,29,30]$. With a stable population of 3.15 million and availability of the data covering different deprivation levels, Wales was an appropriate study site. Morgensen (1982) suggested that ecologic analysis was preferred for evaluating the effectiveness of proposed interventions [31]. Nadanovsky and Sheiham (1995) concluded that personal health services i.e. services provided by health carers were unimportant in explaining the differences in changes of 12 year old caries levels in the 1970s and 80s, suggesting that further ecologic investigation of workforce issues seems appropriate [32]. Area based measures have been promoted by Locker (1993) for research to identify where deprived groups with relatively poor health live [33]. The 22 LHBs show different demographic profiles, some rural and others urban.

There have been improvements in the oral health of 12 year-olds in Wales over the last 20 years. However, there continues to be a visible social inequality as demonstrated by the oral health statistics for the most and least deprived UAs in Wales, Blaenau Gwent and Monmouth, both in the same LHB. The Welsh DMFT in 2000/01 was 1.09 and at 2016/17 was 0.61 . The number of 12 - yearolds experiencing dental caries has reduced from $45.1 \%$ in $2000 / 1$ to $29.6 \%$ in $2016 / 17$ [25]. The mean DMFT for the $29.6 \%$ with caries was 2.05 . This skewed distribution of caries in communities was recognised by Bratthall (2000), using the DMFT for 12-year-olds in eight countries [34]. For all eight countries, the DMFT was below three. However, the closer analysis showed that two thirds of the countries' populations had a DMFT below 1. The DMFT for the other third of the countries' populations was higher than 3 , with the exception of Sweden at 2.82. Bratthall described the DMFT for the third experiencing higher levels of disease as the Significant Caries Index ( $\mathrm{SiC})$. To this end, the $\mathrm{SiC}$ for Wales was 3.39 in 2004, with six of the 22 UAs having a $\mathrm{SiC}$ score less than 3 [25], today all the UAs within LHBs have a SiC score less than 3. The use of the DMFT for those experiencing caries has replaced the need for the $\mathrm{SiC}$.

The percentage experiencing disease showed moderate correlations with the WIMD -0.636, WIMD 50\% 0.545 and GDP sites -0.464 . The correlation between deprivation indexes and percentage of 12-year-olds experiencing diseased is not a new finding as it shows the inequality in oral health in Wales. Interestingly the negative correlation between GDP sites and percentage experiencing disease suggests the greater the number of dental sites, the more people are diseased. This suggests that a proportion of dental workforce is providing oral health care that is not totally based on oral health needs. Rehan (2020), in the context of demand for dental workforce, when asked if more dentists were needed 
stated "if they want to locate in saturated markets or middle- to upper-income urban areas and want a significant self-pay patient base, I would say no." [35]

The dental workforce at 2019 was 0.579 per thousand population, this compares with 0.349 in 2004 [23]. The dental workforce sites correlate with population levels across the country as reflected by a strong correlation of 0.959 and 0.654 with GDP and CDS sites, respectively. Olivia et al. (2020) highlight the fact that NHS dental practices in Wales were not socio-economically distributed, suggesting an equitable spatial availability of services from the viewpoint of the positioning of practices [36]. The fact that CDS sites show a weaker correlation may be explained by the fact that historically they may have been positioned to reflect the greater need within the populations they serve. The moderate correlation of 0.447 between the ratio of dentist per 1000 population and the WIMD most deprived 10\% supports the work of Olivia et al. (2020) and may reflect the decision-making of LHBs with regard to the positioning of dental sites. The negative correlation between population size and the percentage experiencing disease 0.450 suggests that the smaller the population, the greater number of 12-year-olds experience disease. This finding may be explained by the cultural norms within the smaller, usually deprived, populations [37, 38]. The negative correlation was also seen for the $\%$ diseased, and GDP sites -0.464 . Consideration should also be given to the fact that the position of a dental site does not necessarily indicate that the patient profile of the dental site reflects the area deprivation profile as demonstrated by Richards et al. (2005) [39].

As a measure of deprivation, the associations between the WIMD rank average, WIMD most deprived 10\%, WIMD most deprived $50 \%$ for each UA show strong correlations between each measure at WIMD / WIMD 10\% -0.689, WIMD / WIMD 50\% -0.967, WIMD 10\% / WIMD 50\% 0.545 . This would be expected as they are all measuring the same concept, deprivation. However, not all measures showed associations with expected variables suggesting that some are more sensitive than others in different situations. It would be expected that the most deprived $10 \%$ would be associated with DMFT and \%diseased, but no associations were observed here. There was a significant correlation between WIMD rank average and DMFT of 0.653 .

Tickle (2002) has questioned the 80:20 distribution of disease in the community [40]. Using 5-year-old data, he suggested that about half of the population disease was confined to a minority of the population and that the disease active high-risk children were more commonly found in underprivileged area types; they did not live exclusively in small number of deprived areas. This suggests that a change of emphasis towards prevention is required in general dental practice in line with Department of Health directives [41]. Indeed, the Welsh approach to the development of General Dental Services in Wales focuses on prevention as a cornerstone of care [42]. The Welsh response to the Covid-19 pandemic has highlighted this focus on prevention and service delivery [43]. This response will potentially improve access and continuing care to patients with the greatest need while still providing care forlow-risk patients at appropriate levels. Watt (2020) identifies the need to reform service delivery in the context of Covid-19 in accordance with the above [44]. Many workers support change within the dental profession while identifying problematic issues for facilitating change [45-48].

NHS Business Services statistics show that the sixmonthly check-up continues to be a significant patient attendance pattern in general dental practice in England and Wales [43]. It has long been reported that this attendance pattern is of questionable value in terms of health gain. The National Institute for Clinical Excellence (2004) has published its guidelines for routine dental monitoring [49]. Similarly, other decision-making processes currently observed in action in general dental practice are questioned in the National Audit Office report (2004), including routine scaling and polishing [18]. The application of minimally invasive procedures in the presence of a continuing care contract that is risk based is appropriate [50, 51]. It seems that since the new contract of 2006, little leverage has been placed on dentists by the LHBs to change service delivery to incorporate appropriate dental check-up patterns. Furthermore, the monitoring of service delivery by LHBs has focused on equality for dental practitioners rather than equity for patients, however, the response to the Covid-19 crisis has made NHS contracts conditional on risk based continuing care [43]. Richards et al (2020) highlight the fact that contract monitoring has to date, penalised general dental practitioners who wish to operate equitable practice towards their patients [21].

The USWDI showed itself to be a good predictor of health and as such may be of value to service monitors to assess the overall outcome of services. In 2004 similar findings were established using the Glamorgan Dental Index where the investigation of the number of dentists per 1000 population per corresponding WIMD score was undertaken [23].

\section{CONCLUSION}

Since the contract of 2006 there have been improvements in the oral health of 12-year-olds in Wales. The DMFT, DMFT for those experiencing disease and $\%$ of the population experiencing disease have improved. However there continue to be inequalities in the disease experienced at UA levels, and these inequalities are associated with deprivation. While workforce levels have increased, there has been a corresponding improvement in oral health, however deprived subgroups continue to experience relatively higher levels of disease. Coincidentally the $70 \%$ of the 12-year-old population who are healthy tend to receive continued care that is based on an outdated oral health care model, for example, regular six monthly check-ups. This suggests that a proportion of the general dental services delivered in Wales have continued to be based on the principle of supply induced demand for care rather than oral health need. Improving oral health in a diverse population like Wales cannot be achieved by increasing the dental workforce alone. It is necessary to account for levels of deprivation. The USWDI as a predictor of DMFT could be a useful tool to monitor the macro delivery of oral health care for the future in Wales. 


\section{ACKNOWLEDGMENTS}

This work has been initially published as a preprint in Research Square: Wayne Richards, Jamal Ameen, AnneMarie Coll et al. The Balance between Oral Health Needs and Supply Induced Demand in Welsh Dental Services, 20 October 2020, PREPRINT (Version 1) available at Research Square.

DOI: $10.21203 /$ rs.3.rs-94859/v1

\section{COMPETING INTERESTS}

The authors declare no competing interests with this case.

\section{FUNDING SOURCES}

None.

\section{REFERENCES}

[1] Kelly M, Steele J, Nuttall N M, Bradnock G, Morris J, Nunn J, Pine C, Pitts N B, Treasure E, White D, Walker A, Cooper I. Adult Dental Health Survey: Oral Health in the United Kingdom (1998). The Stationary Office : London; 2000.

[2] Jones C. M. Capitation registration and social deprivation in England. An inverse 'dental' care law? $\mathrm{Br}$ Dent J, 2001;190:203-206.

DOI: $10.1038 /$ sj.bdj.4800925

[3] Public Health England (2017) Health Matters: Child Dental Health. [Published 14 June 2017]. Available: https://www.gov.uk/government/publications/healthmatters-child-dental-health

[4] Appleby J, Reed R, Merry L. Root Causes Qualityand Inequality in Dental Health. The health Foundation Nuffield Trust. [Published 2 November 2017] Available: https://www.nuffieldtrust.org.uk/

[5] Watt R, Sheiham A. Inequalities In Oral Health: A Review of the Evidence and Recommendations for Action. Br Dent J. 1999;187: 6-12 DOI: $10.1038 /$ sj.bdj.4800191

[6] Casals E, Gomez A, Cuenca E. Trends in workforce and Utilisation of Dental Services in Catalonia Session C1 Health Services Research 8th Annual Conference of The European Association of Dental Public Health Jyvaskyla Finland

[7] Birch S. The identification of supplier inducement in a fixed price system of healthcare provision: the case of dentistry in the United Kingdom. Journal of Health Economics. 1988;7(2):129-150 DOI: 10.1016/0167-6296(88)90012-4

[8] Oliver A. Reforming Public Sector Dentistry in the UK. British Journal of Health Care Management. 2002; 8 (6): 212-216 DOI: $10.12968 /$ bjhc.2002.8.6.18965

[9] Richards W. Needs and priorities in dental care. British Journal of Health Care Management. 2004;10(6): 178-181 DOI: 10.12968/bjhc.2004.10.6.18715

[10]Bloomfield K. Fundamental review of dental remuneration: Report of Sir Kenneth Bloomfield KCB. London: HMSO; 1992.

[11] Audit Commission. Dentistry Primary Dental Care Services in England and Wales. Northampton: Belmont Press; 2002.

[12]Benn DK. Extending the Dental Examination Interval: Possible Financial and Organizational Consequences. Evidence-Based Dentistry.2002; 3(3):62-63 DOI: $10.1038 /$ sj.ebd.6400128

[13]Dharamsi S, MacEntee MI. Dentistry and distributive justice. Social Science \& Medicine. 2002;55:323-239 DOI: $10.1016 / \mathrm{s} 0277-9536(01) 00174-5$

[14] Taylor G. Modernising NHS Dentistry - Implementing the NHS Plan. Community Dent Health.2000;17(4):207-209.

[15] Department of Health. Government Response to The House of Commons Select Committee On Health's Report on Access to NHS Dentistry.London: Stationary Office; 2016. [Published October 2016]. Available:

\section{AUTHORS' CONTRIBUTIONS}

The participation of each author corresponds to the criteria of authorship and contributorship emphasized in the Recommendations for the Conduct, Reporting, Editing, and Publication of Scholarly work in Medical Journals of the International Committee of Medical Journal Editors. Indeed, all the authors have actively participated in the redaction, the revision of the manuscript, and provided approval for this final revised version.

https://assets.publishing.service.gov.uk/government/uploads Isystem/uploads/attachment_data/file/562506/Response_to primary care A.pdf

[16]Renson T. NHS Dentistry: Options for Change. Primary Dental Care. $2002 ; 9(4): 131-131$ DOI : $10.1308 / 135576102322481965$

[17] National Assembly Government (2002) Routes to Reform Cardiff: NAG

[18] John B. Ensuring effective management of risks Department of Health. London: National Audit Office; 2004-5. [Published 25 November 2004]. Available: https://www.nao.org.uk/wpcontent/uploads/2004/11/040525.pdf

[19] Watson M. The Health and Social Care Bill. Br Dent J. 195: 637-638

[20]UK Government. National Health Service Act 2006. London: 2006. Available: https://www.legislation.gov.uk/ukpga/2006/41/contents

[21] Richards W, Filipponi T, Coll AM. General dental practice and improved oral health: is there a win-win for both the professional establishment and government? $\mathrm{Br}$ Dent J. 2020;228(8):581-585 DOI: $10.1038 / \mathrm{s} 41415-020-1448-3$

[22]Richards W, Ameen JR, Coll AM. Playing the numbers game: Will increasing Dentists Satisfy Oral Healthcare Needs? 2004.Unpublished Available: https://www.researchgate.net/publication/342335065 Playin $\mathrm{g}$ the Numbers Game Will Increasing Dentists Satisfy Oral Healthcare Needs Unpublished paper

[23] Welsh Government. Welsh Index of Multiple Deprivation (WIMD). [Published in November 2019]. Available: www.wimd.gov.wales

[24]Pitts NB, Evans DJ, Nugent ZJ, Pine CM. The dental Caries Experience of 12-year-old children in England and Wales. Surveys Coordinated by the British Association for the Study of Community Dentistry in 2000/2001. Community Dental Health. 2002;19:46-53

[25]Morgan M. Picture of Oral Health 2018: Dental Epidemiological Survey of 12 year olds 2016/17. Cardiff University.[ Published on June 2018]. Available: https://www.cardiff.ac.uk/ data/assets/pdf file/0019/12014 65/Full-Report-Oral-Health-2018.pdf

[26]NHS Business Services Authority FOI. Available:https//:www.applications.nhsbsa.nhs.uk

[27] StatsWales. The Welsh Government's free-to-use online repository for detailed statistical data for Wales. Available: https://statswales.gov.wales

[28]Health in Wales. Find a Dentist. Available: https//:www.wales.nhs.uk

[29] Richards W, Toy A. Improving oral health with the new dental contract CD-ROM. Br Dent J. 2007; 203(8):453-5 DOI: $10.1038 / \mathrm{bdj} .2007 .946$

[30] Welsh Government . Delivery Plan - Together for Health: A National Oral Health Plan for Wales 2013-18. [ Published 2007] Available:

https://www.wales.nhs.uk/document/214894 
[31] Morgenson H. Uses of Ecologic Analysis in Epidemiologic Research. Am J Public Health. 1982; 72(12): 1336-44 DOI: $10.2105 /$ ajph.72.12.1336

[32] Nadanovsky P, Sheiham A. Relative Contribution of Dental Services to the Changes in Caries Levels of 12 year old Children in 18 Industrialized Countries in the 1970s and Early 1980s. Community Dent Oral Epidemiol 1995;23(6): $331-9$

DOI: $\underline{10.1111 / \mathrm{j} .1600-0528.1995 . t b 00258 . \mathrm{x}}$

[33]Locker D. Measuring social inequality in dental health services research: individual, household and area-based measures. Community Dent Health 1993;10(2): 139-5. Available:

[34]Bratthall D. Introducing the Significant Caries Index together with a proposal for new global oral health goal for 12-year-olds. International Dental Journal. 2000;50: 378384

DOI: 10.1111/j.1875-595X.2000.tb00572.x

[35]Rehan K. Demand for Dentists: Forecasting the Future of the Profession Ontario Academy of General Dentistry. Available:

https://www.agd.org/constituent/news/2020/07/06/demandfor-dentists-forecasting-the-future-of-the-profession

[36] Olivia J, Kruger E, Tennant M. Are NHS dental practices socioeconomically distributed in Scotland, Wales and Northern Ireland? Br Dent J. 2020: 229 (1):40-46 DOI: $10.1038 / \mathrm{s} 41415-020-1748-7$

[37]Nassani MZ, Kay EJ, Al-Nahhal TI, Oksayan R, Usumez A, Mohammadi TM. Is the value of oral health related to culture and environment, or function and aesthetics? Community Dental Health. 2015; 32: 204-208

[38] Adair PM, Pine CM, Burnside G, Nicoll AD, Gillett A, Anwar S et al. Familial and cultural perceptions and beliefs of oral hygiene and dietary practices among ethnically and socio-economically diverse groups. Community Dental Health. 2004; 2102-111

[39]Richards W Ameen J Higgs G. Adapting to Change: Dental Prescriptions. Br J Health Care Manage. 2008;14:500-504

[40]Tickle M. The 80:20 phenomenon: help or hindrance to planning caries prevention programmes? Community Dental Health. 2002; 19: 39-42
[41]NHS Dentistry: Delivering Change (2004) DoH

[42]Welsh Government. Taking Oral Health Improvement and Dental Services Forward in Wales. [Published in 2017]. Available:

https://gov.wales/sites/default/files/publications/201903/taking-special-care-dentistry-in-wales-forward.pdf

[43] Restoration of Dental Services Post Covid-19: De-escalation of Red Alert Pandemic Plan. [Published 4 June 2020]. Available https://dental.walesdeanery.org/default/files/202005-11_-restoration-of-dental-services-post-covid19-deescalation-of-red-pandemic-planv315.5.20.pdf.

[44] Watt R. Covid-19 is an opportunity for reform in dentistry The Lancet 2020; 396(10249):462 DOI: $10.1016 / \mathrm{S} 0140-6736(20) 31529-4$

[45] Mossey P . 'Oral health matters': it is time for culture change in dentistry. Br Dent J. 2020;228(11):829-830 DOI: $10.1038 / \mathrm{s} 41415-020-1634-3$

[46] Hurley S.Why re-invent the wheel if you've run out of road? Br Dent J. 2020;228(10):755-756

[47] Holden ACL, Adam L, Thomson WM . The relationship between professional and commercial obligations in dentistry: a scoping review. Br Dent J. 2020; 228(2): 117121

[48]Apelian N Vergnes J N Bedos C (2020) Is the dental profession ready for person-centred care? Br Dent J 2292 133-137 DOI: $10.1038 / \mathrm{s} 41415-020-1195-5$

[49]NICE. Dental checks: intervals between oral health reviews - Clinical guidance. [Published 27 October 2004]. Available : https://www.nice.org.uk/guidance/cg19

[50] Innes NPT, Chu CH, Fontana M, Lo ECM, Thomson WM, Uribe S, Heiland MH, Jepsen S, Schwendicke F. A century of change towards Prevention and Minimal Intervention in cariology. Journal of Dental Research. 2019;98 (6) 611-617 DOI: $\underline{10.1177 / 0022034519837252}$

[51] Kakudate N, Yokoyama Y, Sumida F, Matsumoto Y, Yamazaki H, Toug T, Fujikaw Y. Gordan VV, Gilberth GH. Evidence-practice Gap in Minimal Intervention Dentistry: Findings from a Dental Practice-based Research. J Dent. 2020;102:103469.

DOI : 10.1016/j.jdent.2020.103469 